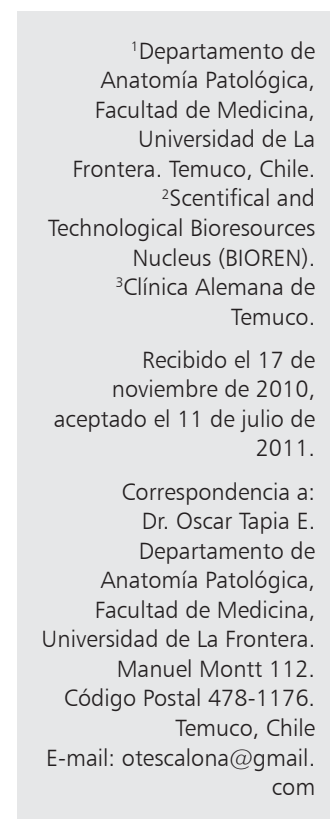

\section{Tumor de células de Sertoli calcificante, de células grandes: caso clínico}

\author{
OSCAR TAPIA E..$^{1,2}$, CLAUDIO MATUS O. ${ }^{3}$, MIGUEL VILLASECA H., ${ }^{1,2}$

\section{Large cell calcifying Sertoli cell tumor. Report of one case}

Sertoli Cell Tumors are less than $1 \%$ of all testicular tumors. We report a 14-yearold male presenting with a left testicular mass. Orchiectomy was carried out and the pathological study informed a large cell calcifying Sertoli cell tumor (LCCSCT). Its association with the Carney complex and Peutz-Jeghers Syndrome was subsequently discarded. Surgical excision was completed with a radical orchiectomy. After eight months of follow up, there is no evidence of tumor relapse.

(Rev Med Chile 2011; 139: 1330-1335).

Key words: Adolescent; Orchiectomy; Sertoli-Leydig cell tumor.

\footnotetext{
I
}

os tumores testiculares de la línea no germinal representan aproximadamente el $5 \%$ $\checkmark$ de las neoplasias originadas en este órgano, conformando este grupo aquellos tumores derivados del estroma y de los cordones sexuales. Dentro de este grupo encontramos al tumor de células de Sertoli (TCS), entidad clínico-patológica infrecuente que representa menos de $1 \%$ de todos los tumores testiculares, siendo el tumor calcificante de células grandes de Sertoli (TCCGS) un subtipo extremadamente infrecuente de TCS con tan sólo alrededor de 70 casos reportados en la literatura ${ }^{1-4}$. Estos tumores tienden a presentarse en forma bilateral y multifocal, con un comportamiento biológico benigno en la mayoría de los casos, pudiendo ser su forma presentación aislada o asociado a síndromes displásicos ${ }^{4-8}$.

Presentamos el caso de un escolar de 14 años con un TCCGS diagnosticado en la Unidad de Anatomía Patológica del Hospital Hernán Henríquez Aravena de Temuco.

\section{Caso clínico}

Paciente de sexo masculino de 14 años, sin antecedentes mórbidos, quien consultó luego de sufrir trauma de baja intensidad (pelotazo) en zona genital.
$\mathrm{Al}$ examen físico presentaba dolor que dificultaba la palpación, evidenciándose un aumento de volumen asimétrico testicular izquierdo, sin otras lesiones asociadas. Se solicitó ecotomografía testicular presentándose a control luego de transcurridos 5 meses, constatándose clínicamente una masa indurada en testículo izquierdo de aproximadamente $2 \mathrm{~cm}$ de diámetro mayor, no dolorosa y sin compromiso escrotal; testículo derecho y pene sin alteraciones. La ultrasonografía demostró en el espesor del testículo izquierdo un nódulo de $18 \times 19$ x 15 mm, bien delimitado, de paredes hiperecogénicas con sombra acústica posterior. El testículo derecho, epidídimos y cordones espermáticos no presentan alteraciones de su ecoestructura (Figura 1A-C). El estudio serológico para marcadores tumorales $(\alpha$-feto proteína y hormona gonadotropina coriónica sub-unidad $\beta$ ) fueron normales. Se complementó estudio con tomografía computada (TC) de pelvis, abdomen y tórax las que no demostraron lesiones secundarias.

Se efectuó enucleación del tumor y biopsia intra-operatoria. Se examinó un fragmento de tejido testicular de $5 \mathrm{~g}$ de $35 \times 17$ x $15 \mathrm{~mm}$ presentando en la superficie de corte una lesión subcapsular redondeada, bien delimitada, amarillenta, de consistencia firme de $22 \mathrm{~mm}$ de diámetro mayor, con áreas grumosas de aspecto arenoso (Figura 
Tumor de células de Sertoli calcificante de células grandes - O. Tapia et al

1D y 1E). El corte histológico por congelación y diferido demostró una lesión que presentaba nidos y cordones conformados por células ovales a poligonales de núcleos grandes, excéntricos y con nucléolo prominente, el citoplasma es eosinófilo y abundante, apreciándose infiltrado inflamatorio polimorfonuclear neutrófilo en la región central del tumor y linfocitos en la periferia en partes formando agregados linfoides. El estroma es en partes hialino con áreas de degeneración mixoide y abundantes calcificaciones dispuestas a nivel intersticial y en el lumen de los nidos tumorales, concluyéndose en la biopsia contemporánea un tumor de células de Sertoli calcificado (Figura 2). No se observó extensión tumoral intratubular, figuras mitóticas, necrosis, acentuada atipía citológica ni extensión tumoral extra-testicular. El estudio inmunohistoquímico demostró intensa positividad para $\alpha$-inhibina, $S-100$ y vimentina; con un índice de proliferación $(\mathrm{Ki}-67)$ bajo $(<1 \%)$ (Figura 3).
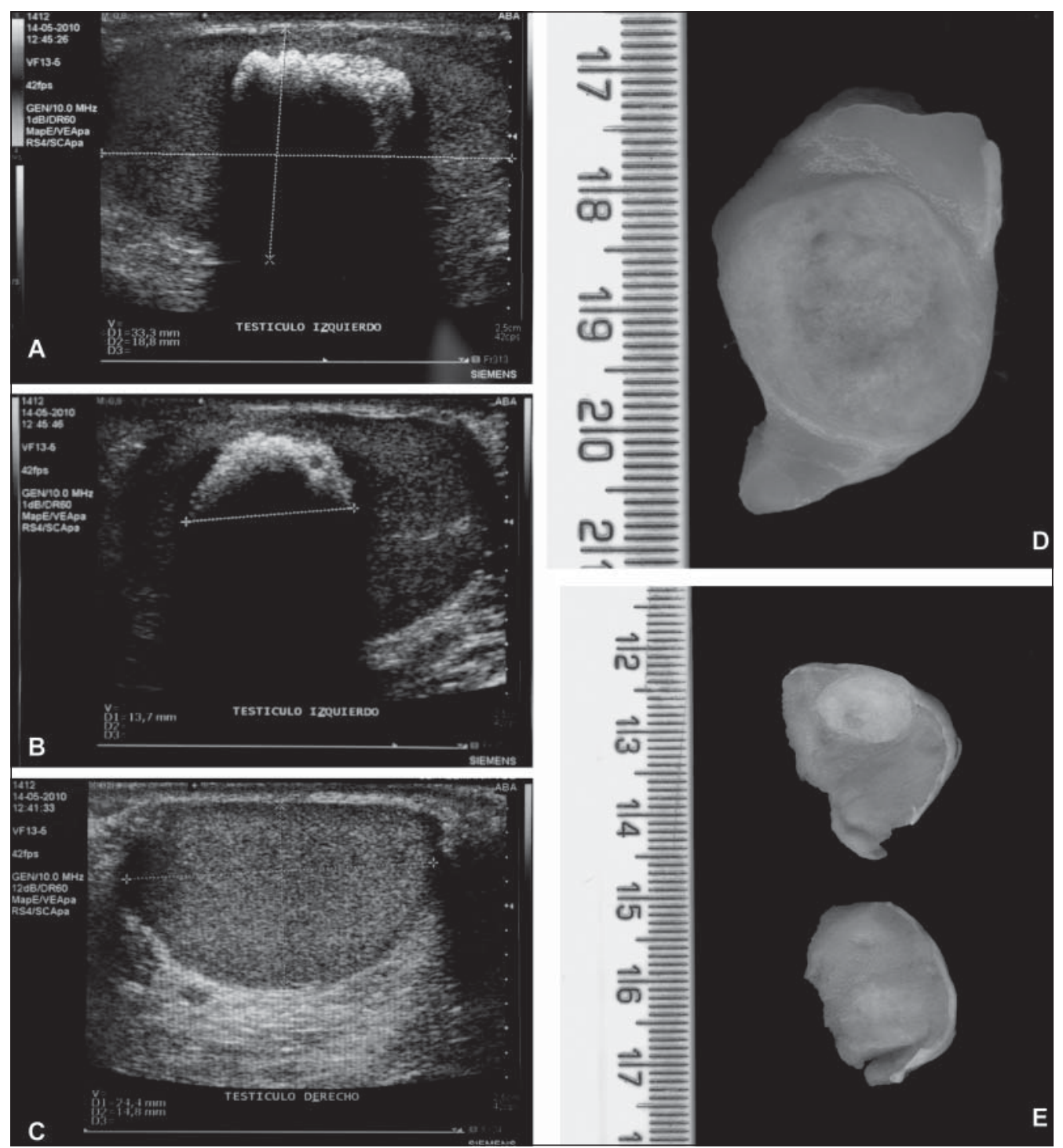

Figura 1. En testículo izquierdo (A y B), se aprecia nódulo de bien delimitado con áreas hiperecogénicas que proyectan sombra acústica posterior. El testículo derecho sin alteraciones de su ecoestructura (C). Macroscópicamente se reconoce lesión tumoral subcapsular, redondeada, amarillenta con áreas pardo grisáceas ( $D$ y E). 

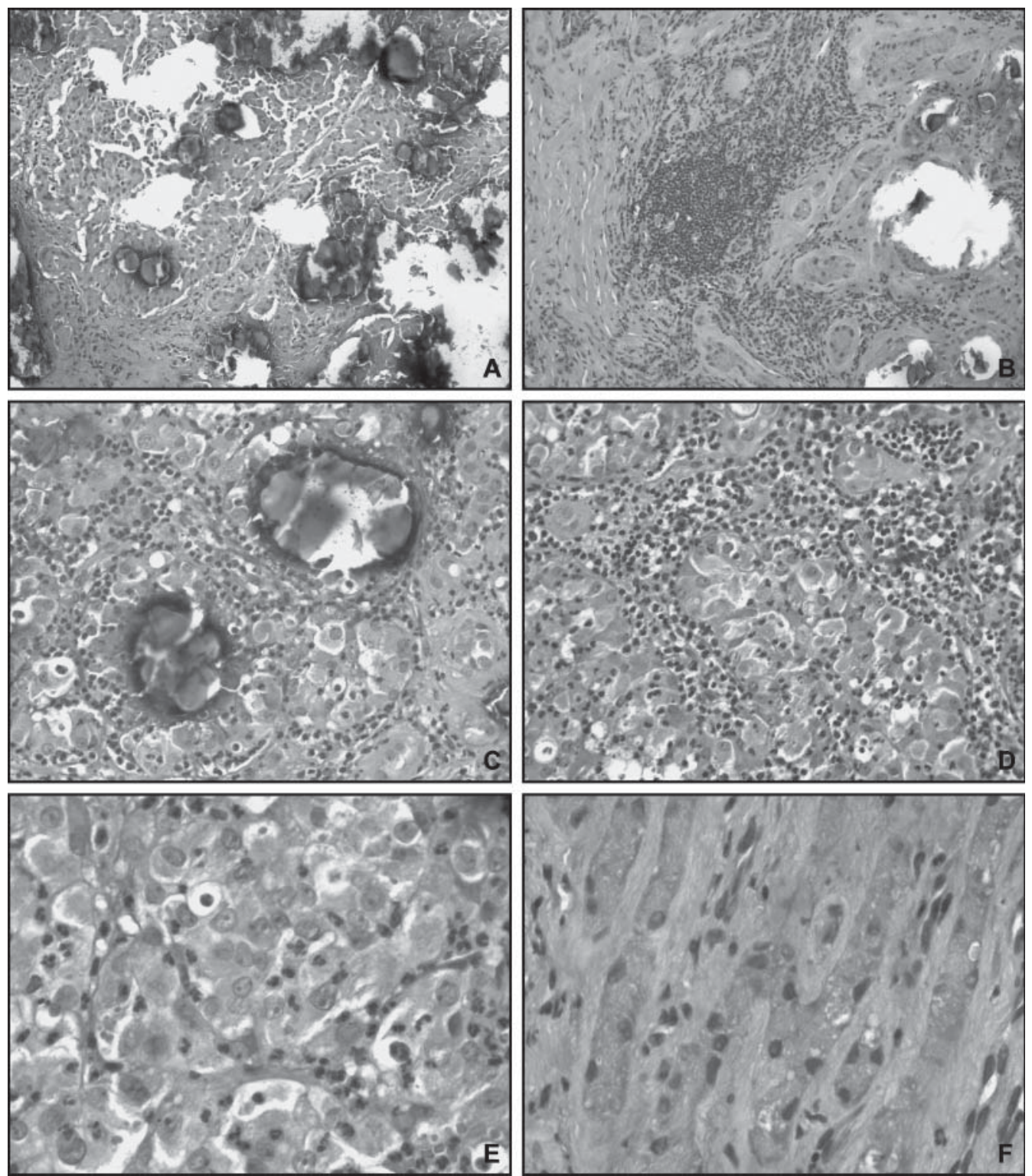

Figura 2. (H-E, A-B: 40x, C-D: 100x, E-F: 200x). A-C: Lesión tumoral con abundantes focos de calcificación distrófica y presencia de infiltrado linfocitario en la periferia. D-F: Nidos y cordones de células ovales con núcleos grandes, nucléolo prominente, citoplasma eosinófilo con polimorfonucleares neutrófilos entre las células tumorales y estroma con áreas de degeneración mixoide.

Se completó la cirugía realizándose orquiectomía radical. No se registraron complicaciones post-operatorias. A los 8 meses post-cirugía, el paciente se encuentra sano, sin evidencia de enfermedad en TC de tórax-abdomen y pelvis; descartándose en este paciente la asociación con complejo de Carney y síndrome de Peutz-Jeghers.

\section{Discusión}

Los tumores de la línea no germinal representan aproximadamente el 5\% de las neoplasias originadas en el testículo, conformando este grupo aquellos tumores derivados del estroma y cordones sexuales. Dentro de este grupo encontramos al 

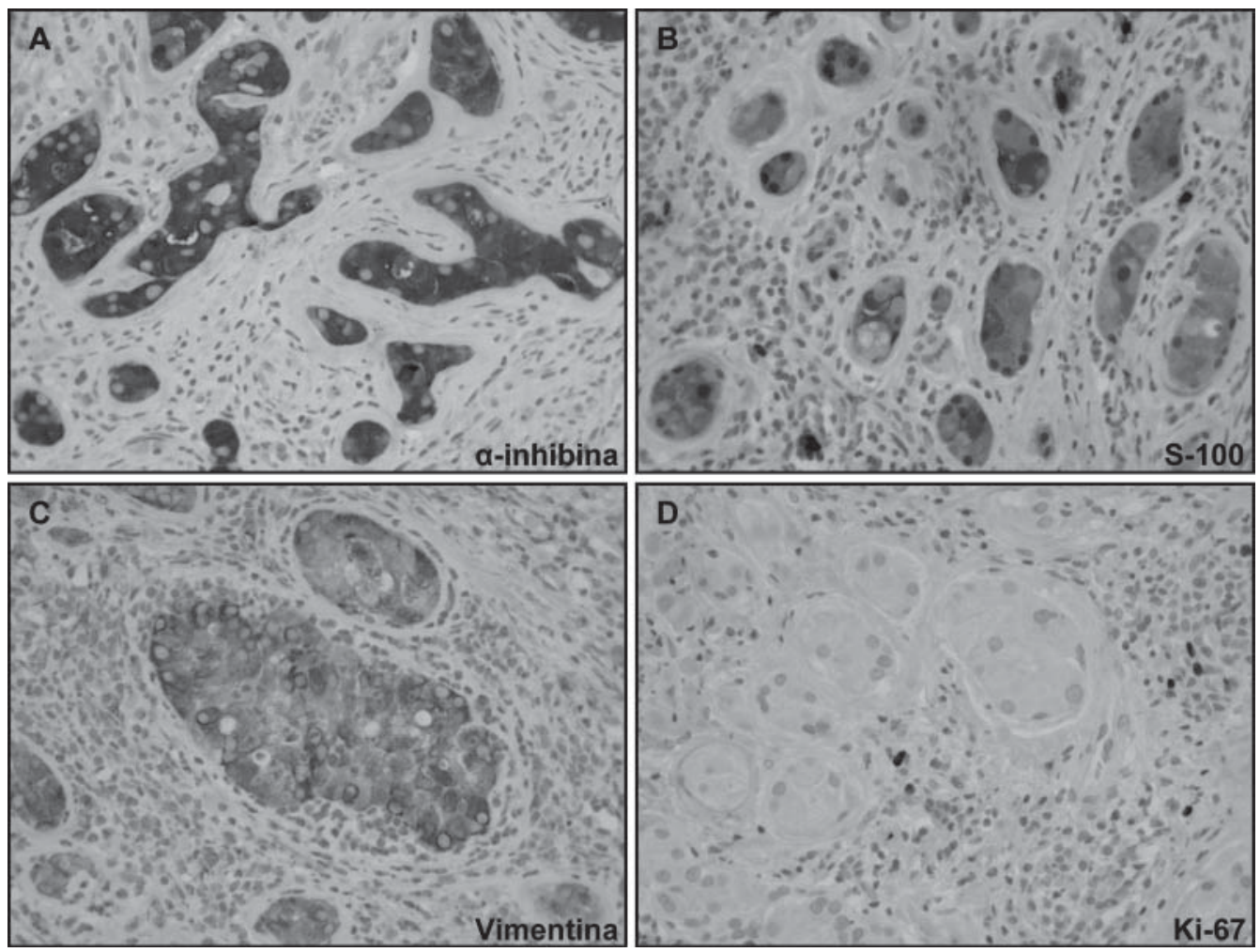

Figura 3.

TCS, entidad clínico-patológica con aproximadamente 100 casos descritos en la literatura y que representa menos de $1 \%$ de todos los tumores testiculares. El TCCGS corresponde a un raro subtipo de TCS descrito por primera vez en 1980 por Proppe y Scully, quienes reportaron 10 casos de pacientes afectados por este tumor; existiendo hoy en día tan sólo alrededor de 70 casos documentados en la literatura ${ }^{1-5,9}$.

El TCCGS afecta mayoritariamente a hombres menores de 20 años, pudiendo clínicamente manifestarse con ginecomastia y pubertad precoz hasta en $42 \%$ de los pacientes, esto último explicado por la producción de hormonas esteroidales tanto por las células de Sertoli neoplásicas como por las células de Leydig extratumorales; en el caso presentado no se observaron manifestaciones endocrinas secundarias; hecho que puede explicarse por la menor masa celular productora de estas hormonas determinada por el pequeño tamaño tumoral ${ }^{2,7,9-11}$.

De acuerdo a la edad de los pacientes afectados es posible reconocer dos grupos: uno de afectación temprana (edad media a los 17 años) y otro de afectación tardía (alrededor de los 40 años); presentando este último grupo un mayor riesgo de malignización ${ }^{2}$. Por otro lado, de acuerdo a su forma de presentación se reconocen dos grupos: uno de presentación aislada o no asociado a síndromes displásicos (60\% de los casos), donde los tumores son habitualmente unilaterales y unifocales, y otro que se presenta asociado a síndromes displásicos con herencia autosómico dominante ( $40 \%$ de los casos); siendo complejo de Carney (33\%) y síndrome de Peutz-Jeghers las principales asociaciones; por lo que es necesario realizar un examen clínico riguroso para descartar la coexistencia con alguno de estos síndromes que requieran tratar oportunamente las patologías asociadas a ellos (mixoma auricular, carcinoma tiroideo, schwanoma melanótico psamomatoso, adenoma hipofisiario, pólipos hamartomatosos gastrointestinales, entre otras $)^{5,8,12,13}$. El caso reportado representa una forma de presentación 
temprana (14 años) y aislada, descartándose en los exámenes clínicos y de imágenes posteriores la asociación con alguno de los síndromes displásicos más frecuentemente descritos.

Si bien los hallazgos de la ecotomografía testicular, durante el estudio pre-operatorio no son específicos, presentan un alto valor diagnóstico permitiendo evidenciar la presencia de focos hiperecogénicos con sombras acústicas producto de las calcificaciones, debiendo considerar el diagnóstico diferencial cuadros infecciosos (tuberculosis), calcificaciones post-traumática y otras neoplasias testiculares (teratoma, carcinoma embrionario, carcinoide $)^{11,12,14}$.

Macroscópicamente los TCCGS son habitualmente masas firmes, menores de $4 \mathrm{~cm}$, bien circunscritos, no encapsulados, amarillo grisáceos $\mathrm{y}$ con un aspecto arenoso producto de las microcalcificaciones. Son bilaterales hasta en $44 \%$, frecuencia mayor aún cuando se presentan asociados a síndromes displásicos (78\%). Microscópicamente están formados por nódulos, nidos y cordones conformados por células ovales a poligonales de 12 a 35 micras con núcleos grandes, excéntricos y nucléolo prominente, citoplasma eosinófilo y abundante, con polimorfonucleares neutrófilos en la región central y linfocitos dispuestos en la periferia, el estroma es mixoide o fibroso, pudiendo observarse extensión neoplásica intratubular y calcificaciones hasta en 50\% de los casos. Las mitosis son infrecuentes y la atipía nuclear leve, debiendo hacer sospechar características de malignidad la presencia de marcado pleomorfismo nuclear, necrosis, alto índice mitótico y compromiso extratesticular y/o linfovascular. El estudio inmunohistoquímico por su parte demuestra positividad para $\alpha$-inhibina, vimentina y S-100 mientras que CD99, $\alpha$-fetoproteína, $\beta$-gonadotrofina coriónica humana, fosfatasa alcalina placentaria y melan-A no muestran inmunoreactvidad ${ }^{4-8,15-17}$.

Si bien el TCCGS presenta un comportamiento biológico incierto, en $83 \%$ de los casos su comportamiento es benigno, por lo que puede considerarse como una neoplasia de bajo potencial maligno, sin embargo, si dos o más características clínico-morfológicas tales como: tamaño tumoral mayor de $4 \mathrm{~cm}$ (tamaño promedio lesiones benignas $1,4 \mathrm{~cm}$ ), lesiones unilaterales y/o unifocales, afectación de pacientes de mayor edad (promedio de edad de casos benignos y malignos 17 años y 39 años respectivamente), extensión tumoral extratesticular (cordón espermático, epidídimo o túnica albugínea), necrosis y/o hemorragia, atipía nuclear acentuada, recuento mitótico mayor a 3/10 campos de aumento seco mayor, índice de proliferación (Ki-67) elevado e invasión linfovascular; están presentes, sugieren un curso más agresivo o francamente maligno con desarrollo de metástasis tanto por vía linfática a ganglios retroperitoneales como hematógena con diseminación a hueso, pulmones e hígado ${ }^{4,5,18,19}$. Nuestro caso presenta como único factor de riesgo el hecho de ser un tumor unilateral y unifocal, lo que hace suponer el probable curso benigno del tumor en este paciente.

Respecto al tratamiento este debe ser quirúrgico, existiendo distintas recomendaciones de acuerdo a si el compromiso es uni o bilateral. Para lesiones unilaterales se recomienda realizar orquiectomía radical teniendo siempre presente la necesidad de efectuar controles periódicos al testículo contralateral, más aún si se presenta asociado a complejo de Carney. Para tumores bilaterales es posible realizar enucleación del tumor u orquiectomía parcial de manera de preservar la fertilidad, debiéndose siempre realizar controles clínicos e imageneológicos periódicos al tejido testicular remanente, sin embargo, y dada la frecuente multifocalidad de estos casos el tratamiento recomendado es la orquiectomía radical ${ }^{4,6-8,20}$.

En resumen, presentamos un paciente de sexo masculino de 14 años con una masa testicular izquierda en la cual el estudio histopatológico intraoperatorio informó una infrecuente neoplasia no germinal derivada del estroma y cordones sexuales: TCCGS; entidad clínico-patológica ha tener presente dentro de los diagnósticos diferenciales ante la pesquisa de una masa testicular en la cual se demuestra la presencia de calcificaciones durante el estudio imagenológico pre-operatorio.

\section{Referencias}

1. Ulbright TM, Amin MB, Young RH. Tumors of the testis, adnexa, spermatic cord, and scrotum. Atlas of Tumor Pathology, 3rd Series, Fascicle 25, Washington DC: Armed Forces Institute of Pathology. 1999.

2. Giglio M, Medica M. Testicular Sertoli cell tumours and relative subtypes. Urol Int 2003; 70: 205-10.

3. Blix GW, Levine LA, Goldberg R. Large cell calcifying Sertoli cell tumor of the testis. Scand J Urol Nephrol 1992; 26: 73-5.

4. Shanks JH, Iczkowskiw KA. Non-germ cell tumours of 
the testis. Current Diagnostic Pathology 2002; 8: 83-93.

5. De Raeve H, Schoonooghe P, Wibowo R, Van Marck E, Goossens A. Malignant Large Cell Calcifying Sertoli Cell Tumor of the Testis. Pathol Res Pract 2003; 199: 113-7.

6. Shin SH, Outwater E. Benign Large Cell Calcifying Sertoli Cell Tumor of the Testis in a Prepubescent Patient. AJR 2007; 189: W65-6.

7. Chang B, Borer J, Tan P, Diamond D. Large-cell calcifying Sertoli cell tumor of the Testis: case report and review of the literature. Urology 1998; 52: 520-3.

8. Aristi-Urista G, Bezzerri-Colonna M, González-Mena L, Duarte-Torres R, Manzanilla-García H. Tumor calcificante de células grandes de Sertoli. Rev Med Hosp Gen Mex 2005; 68: 24-30.

9. Proppe KH, Scully RE. Large-cell calcifying Sertoli cell tumour of the testis. AmJ Clin Pathol 1980; 74: 607-19.

10. Pérez-Atayde AR, Núñez AE, Carroll WL. Large cell calcifying Sertoli cell tumor of the testis. Cancer 1983; 51: 2287-92.

11. Candanedo F, Córdova C, Mora L. Características ultrasonográficas y morfológicas del tumor de células de Sertoli, calcificante de células grandes, testicular en un adolescente de 17 años. Patología 2007; 45: 141-3.

12. Inzulza A, Krstulovic Y. Tumor testicular calcificante de celulas grandes de Sertoli: comunicacion de un caso. Rev Chil Radiol 2006; 12: 135-8.

13. Carney JA, Gordon H, Carpenter PC, Shenoy BV, Go VL. The complex of myxomas, spotty pigmentation and endocrine overactivity. Medicine 1985; 64: 270-83.

14. Gierke C, King B, Bostwick D, Choyke P, Hattery R.
Large-Cell Calcifying Sertoli Cell Tumor of the Testis: Appearance at Sonography. AJR 1994; 163: 373-5.

15. Tetu B, Ro J, Ayala A. Large-cell calcifying Sertoli cell tumor of the testis. A clinicopathological, immunohistochemical and ultrastructural study of two cases. Am J Clin Pathol 1991; 96: 717-22.

16. Tanaka Y, Carney J, Ijiri R, Kato K, Miyake T, Nakatani Y et al. Utility of immunostaining for S-100 protein subunits in gonadal sex cord-stromal tumors, with emphasis on the large-cell calcifying Sertoli cell tumor of the testis. Hum Pathol 2002; 33: 285-9.

17. Petersson F, Bulimbasic S, Sima R, Michal M, Hora M, Dominguez $\mathrm{H}$, et al. Large cell calcifying Sertoli cell tumor: a clinicopathologic study of 1 malignant and 3 benign tumors using histomorphology, immunohistochemistry, ultrastructure, comparative genomic hybridization, and polymerase chain reaction analysis of the PRKAR1A gene. Human Pathology 2010; 41: 552-9.

18. Nogalez FF, Andújar A, Zuluaga A. Malignant lare cell calcifying Sertoli cell tumor of the testis. J Urol 1995; 15: 1935-7.

19. Kratzer SS, Ulbright TM, Talerman A, Srigley JR, Roth LM, Wahle GR et al. Large cell calcifying Sertoli cell tumor of the testis: contrasting featurez of six malignant and six benign tumors and a review of the literature. Am J Surg Pathol 1997; 21: 1271-80.

20. Brown B, Ram A, Clayton P, Humphrey G. Conservative management of bilateral Sertoli cell tumors of the testicle in association with the Carney complex: a case report. J Ped Surg 2007; 42: E13-5. 